\title{
TIME-TEMPERATURE CURVE DEFINITION ACCORDING TO FUEL TYPE
}

An idealized temperature curve of compartment fire has three, distinct phases: growth phase - development phase from ignition to flashover, steady-burning phase, and decay phase. The experimental results performed in recent years show that the standard temperature curve proposed by the International Standards Organization (ISO) as well as ASTM E119 time-temperature curve selected for a standard fire resistance test do not satisfactorily describe fire phases for different fuel types. In this paper we propose the definition of the time-temperature curve by means of a unique function in which the fuel type is defined with parameters.

Key words: temperature curve, adaptive control, software

\section{Introduction and background}

Generalization of the unique temperature-time fire curve is very complicated because many parameters as ignitability and combustibility of fire material, rate of heat release, flame spread, etc. are included. Further, shape of the temperature-time curve depends on parameters as open doors or windows, vent flows and others.

No single time-temperature curve can represent all fires because there are many ways in which the fire can develop after ignition. However, the most fire curves are similar in their growth phases, independently of fuel type. In Fig. 1 fire curves for different kinds of fuels and for different quantity of the same fuel (fuel: rubber) are shown.

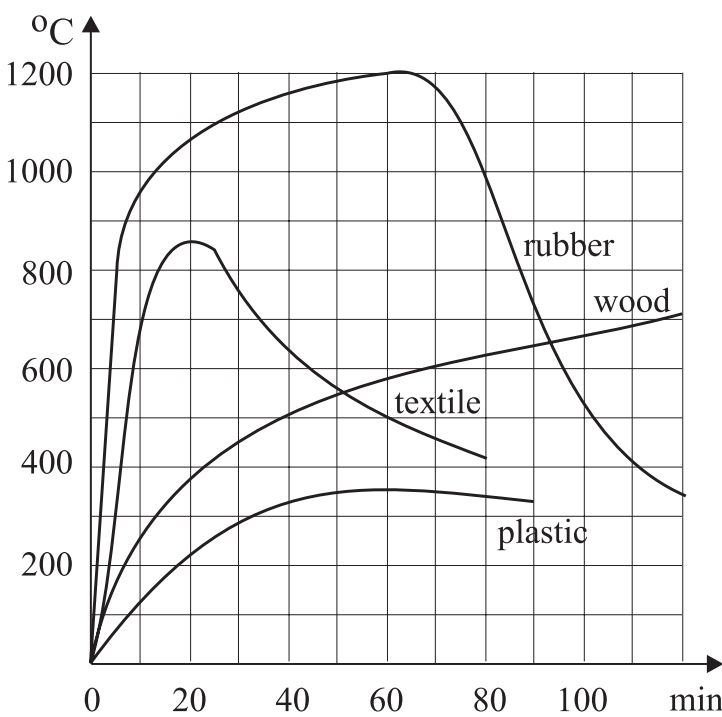

An idealized temperature curve of compartment fire has three, distinct phases: growth phase - development phase from ignition to flashover, steady-burning (fully developed) phase, and decay phase. In most cases the front edge of a fire signal may be considered to be a reliable confirmation about fire growth. The growth phase has primary importance for obtaining a realistic prediction of detector and sprinkler activation, time to start evacuation, and time to initial exposure of occupants. Moreover, with suitable analytical function, which describes the growth phase, it is possible very fast - immediately after ignition, to predict the temperature development, its maximal value, and the time interval needed to achieve this value.

Fig. 1 Fire curves for different types of fuel (on the left), and fire curves for different quantities of the same fuel (on the right)

\footnotetext{
* Milan Dj. Blagojevich

Faculty of Occupational Safety, Carnojevica 10a, 18000 Nish, Yugoslavia, E-mail: milan@znrfak.znrfak.ni.ac.yu
} 
In order to design an appropriate time-temperature curve it is necessary to know some facts about the growth, steady burning and decay phases of fire.

From the previous figures it is obvious that the growth phase of fire may be treated like pulse phenomena. This means that it is possible to approximate the fire growth phase with Heaviside function, with a linear combination of exponential functions or with some suitable function that satisfactory describes the pulse phenomena. The steady burning phase - the phase of fully developed fire may be at a sub-flashover or post-flashover level. This phase may originate with or without flashover. At the post-flashover level the steady burning phase is fuel or ventilation controlled. From this reason, the shape of the time-temperature curve will have characteristic peak before the decay phase - in a point of flashover, or slow decrease before the decay phase - in absence of flashover.

The decay phase is characterized with a fast decrease because a burning rate declines as the fuel is exhausted. In engineering applications and in absence of experimental data, this phase may be considered as the inverse of the growth phase. It is often assumed that the decay phase begins when $20 \%$ of fuel is left. With this assumption, the inverse shape of the decay phase from the growth phase is technically reasonable. The previous consideration is illustrated in Fig. 2.

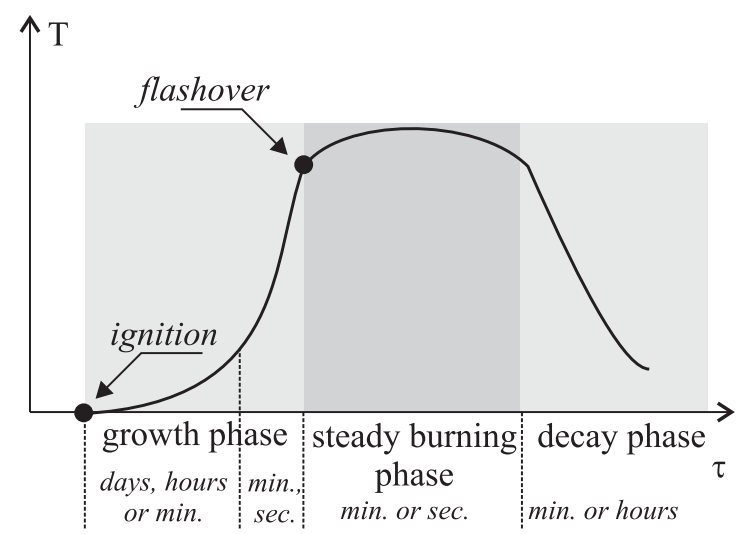

Fig. 2 Schematic presentation of time-temperature phases (an idealized fire curve)

\section{Time-temperature curves in engineering applications}

Physical modeling does not always involve major reductions in a physical scale. Physical models, in general, simplify complex phenomena in a manageable and understandable way. An example of this type of physical modeling is the well known ASTM E119 fire-resistance test. The ASTM E119 time-temperature curve shown in Fig. 4 was selected as a representative time-temperature curve for testing structural assemblies. The furnace environment is intended to model the fire environment experienced by structural members in a fire.
On the other hand, in many engineering applications the standard time-temperature relationship according to ISO 834 can be used:

$$
T= \begin{cases}T_{0}+504 \tau^{0.141} & \tau<10 \mathrm{~min} \\ T=T_{0}+345 \log (8 \tau+1) & \tau \geq 10 \mathrm{~min}\end{cases}
$$

where: $T_{0}$ - temperature at the start of the fire, $\left[{ }^{\circ} \mathrm{C}\right]$

$T$ - temperature in the compartment, $\left[{ }^{\circ} \mathrm{C}\right]$, and

$\tau$ - time [min]

These representative time-temperature curves are shown in Fig. 3. and regardless many limitations observed over the past decades, these models are still widely used.

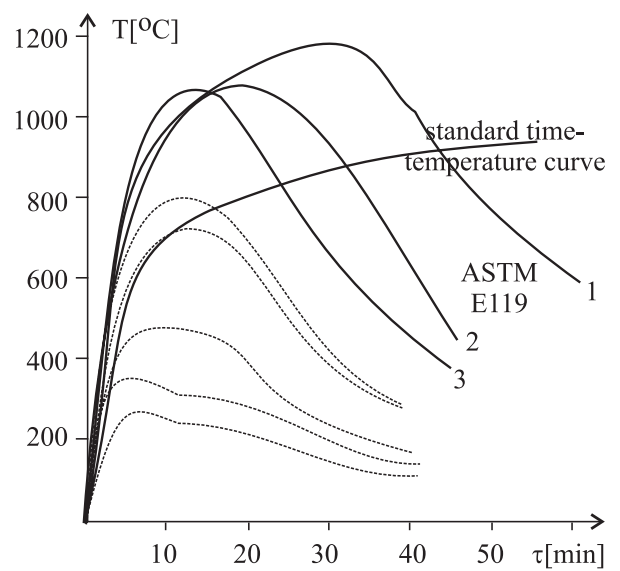

Fig. 3 ASTM E119 curves and standard time-temperature curve

The basic idea presented in this paper is to define the family of curves that satisfactorily and accurately describe the phases of fire. With this approach, each of the curves differs only in one parameter - according to fuel type.

\section{The new function for time-temperature relationship}

For approximation of the fire phases we suggest, as very simple and accurate, the following function:

$$
T=T_{\max }\left[\frac{\tau}{\tau_{\max }} e^{\left(1-\frac{\tau}{\tau_{\max }}\right)}\right]^{c}
$$

where: $T$ - temperature $\left[{ }^{\circ} \mathrm{C}\right]$,

$\tau$ - time [s],

$T_{\max }$ - maximal temperature in steady burning phase $\left[{ }^{\circ} \mathrm{C}\right]$,

$\tau_{\max }$ - time instance for maximal temperature $\left[{ }^{\circ} \mathrm{C}\right]$,

$e$ - parameter that depends on fuel type.

In Fig. 4. the curves in accordance to the function defined with (2) for values $c>1$ and $c<1$ are shown. The parameter $c$ that defines fuel type is, in fact, the rate of rise of the given function. 


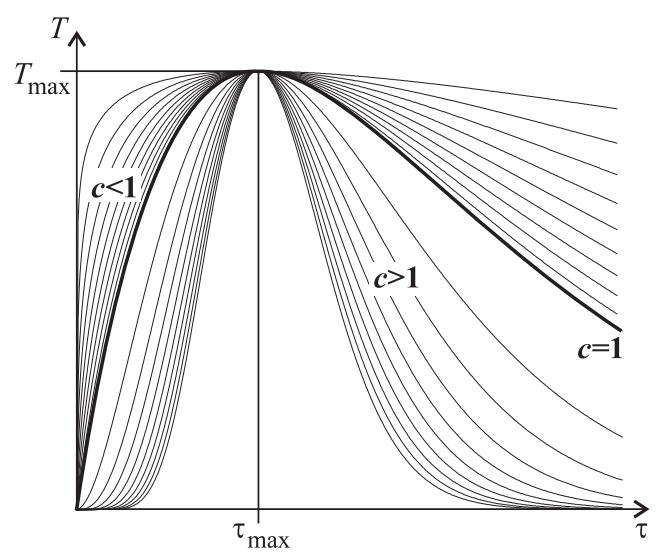

Fig. 4 Time-temperature curves

In order to prove the proper choice of function (2) for time-temperature, we must know the value of maximal temperature raised during the steady burning phase and the time instance for maximal temperature. In this way, it is necessary to find only a parameter $c$. On the other hand, it is obvious that the shape of curves shown in Fig. 4. can be used to describe a time-temperature process for the most fires, especially flaming ones (with characteristic peak). For smouldering fires, this function can be used only for the growth phase of fire - between ignition and flashover.

\section{Using the new function}

The function given with (2) can be used in the following way: if we know the maximal temperature of fire and the corresponding time coordinate, the parameter $c$ can be calculated by adjusting the function to the accurate value in any point $\left(\tau_{1}, \mathrm{~T}_{1}\right)$ in the growth phase. ),

The adjusting of function (2) in point $\left(\tau_{1}, \mathrm{~T}_{1}\right)$ gives:

$$
c=\frac{\ln \frac{T_{1}}{T_{\max }}}{\ln \frac{\tau_{1}}{\tau_{\max }}+1-\frac{\tau_{1}}{\tau_{\max }}}
$$

For numerical experiments and for illustration of this approach, some curves from Fig. 1. and Fig. 3. were chosen. The aim was to compare shapes of the experimental curves with curves obtained by approximation.

The results of numerical experiments are shown in Fig. 5. and in table 1.

The new function can also be applied on ASTM E119 curves, as shown in Fig. 6 and table 2.

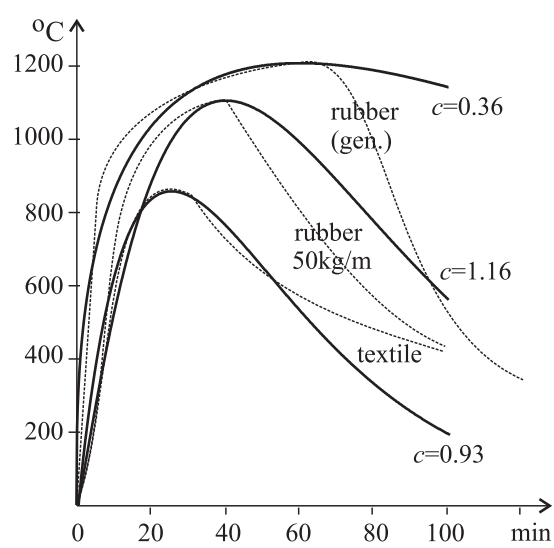

Fig. 5 Time-temperature and approximation curves

Results of approximation with function (2)

Table 1 for different types of fuel (rubber and textile)

\begin{tabular}{|c|c|c|c|}
\hline \multicolumn{4}{|c|}{ Approximations for curves from Fig. 1. } \\
\hline$\tau[\mathrm{s}]$ & $\begin{array}{c}T\left[{ }^{\circ} \mathrm{C}\right] \text { rubber } \\
\text { (gen.) }\end{array}$ & $\begin{array}{c}T\left[{ }^{\circ} \mathrm{C}\right] \text { rubber } \\
(50 \mathrm{~kg} / \mathrm{m})\end{array}$ & $\begin{array}{c}T\left[{ }^{\circ} \mathrm{C}\right] \\
(\text { textile) }\end{array}$ \\
\hline 600.00 & 850.16 & 633.14 & 545.59 \\
\hline 1200.00 & 1027.36 & 831.88 & 889.11 \\
\hline 1800.00 & 1119.48 & 836.12 & 1055.26 \\
\hline 2400.00 & 1169.27 & 753.09 & 1100.00 \\
\hline 3000.00 & 1193.26 & 638.73 & 1067.92 \\
\hline 3600.00 & 1200.00 & 521.54 & 991.17 \\
\hline 4200.00 & 1194.61 & 414.82 & 891.82 \\
\hline & $c=0.36$ & $c=0.93$ & $c=1.10$ \\
\hline
\end{tabular}

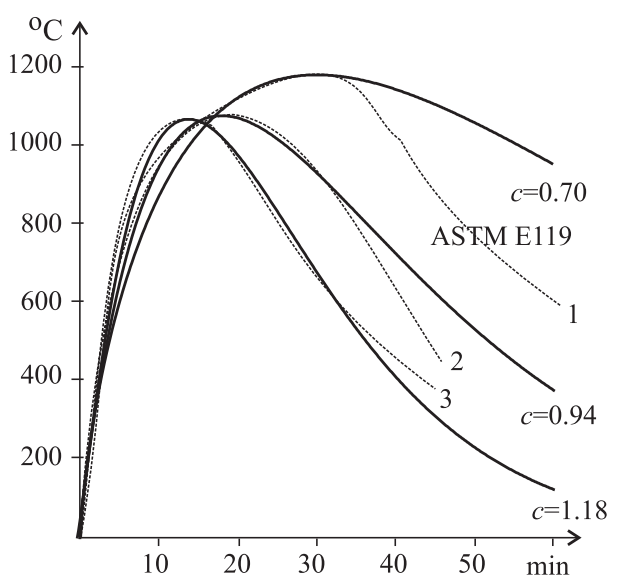

Fig. 6 Time-temperature and approximation curves 
Results of approximation with function (2) for ASTM curves

\begin{tabular}{|c|c|c|c|}
\hline \multicolumn{4}{|c|}{ Approximations for ASTM curves from Fig. 6.} \\
\hline$\tau[\mathrm{s}]$ & $T\left[{ }^{\circ} \mathrm{C}\right]-1$ & $T\left[{ }^{\circ} \mathrm{C}\right]-2$ & $T\left[{ }^{\circ} \mathrm{C}\right]-3$ \\
\hline 150.00 & 391.61 & 380.69 & 370.24 \\
\hline 300.00 & 601.35 & 639.87 & 678.60 \\
\hline 450.00 & 754.26 & 821.41 & 886.41 \\
\hline 600.00 & 870.85 & 944.28 & 1007.93 \\
\hline 750.00 & 960.83 & 1021.84 & 1062.24 \\
\hline 900.00 & 1030.11 & 1064.28 & 1066.94 \\
\hline 1050.00 & 1082.72 & 1079.60 & 1036.69 \\
\hline 1200.00 & 1121.63 & 1074.20 & 983.15 \\
\hline 1350.00 & 1149.14 & 1053.16 & 915.24 \\
\hline 1500.00 & 1167.08 & 1020.60 & 839.65 \\
\hline 1650.00 & 1176.95 & 979.77 & 761.24 \\
\hline 1800.00 & 1180.00 & 933.28 & 683.45 \\
\hline 1950.00 & 1177.27 & 883.22 & 608.59 \\
\hline 2100.00 & 1169.66 & 831.21 & 538.15 \\
\hline 2250.00 & 1157.92 & 778.52 & 473.01 \\
\hline & $c=0.70$ & $c=0.94$ & $c=1.18$ \\
\hline
\end{tabular}

Table 2

\section{Conclusion}

Time-temperature curves having the shape similar to pulse phenomena are very convenient for approximation. For smouldering fires (without characteristic peak) this function can be used for approximation of the development phase of fire. In any way, this function provides significantly better results related to the already known standard time-temperature curves. The type of fuel can be defined by only one parameter or by couple of values of this parameter.

The method described in the above text is complex and, therefore, can be useful in reconstruction of fire. It is necessary to know most of the data before approximation and, consequently, this method may not be used in real time, during the fire data acquisition. Unfortunately, when all of the data are known, the fire is fully developed, and no prediction has any sense.

\section{References}

[1] ABRAMOWITZ, M., STENGUN, I.: Handbook of mathematical functions, Dover publications, New York, 1964.

[2] BLAGOJEVICH, M., PETKOVICH, D.: Detecting fire in early stage - a new approach, Facta Universitatis, Facta Universitatis, Series: Working and Living Environmental Protection, Vol. 2, No 1, 2001, pp. 19-26.

[3] JANSSENS, L. M.: Heat release rate (HRR), FORUM Workshop of Measurement Needs for Fire Safety, NIST, USA, 2000.

[4] JONES, W.W, FORNEY, P. G.: Comparison of CFAST prediction to real-scale-fire tests, Proceedings of Fire Safety Conference on Performance Based Concepts, Switzerland, 1996.

[5] PITTS, M.W.: Temperature measurements in fire, Proceedings of FORUM Workshop on Measurement Needs for Fire Safety, NISTIR 6527, NIST, USA, 2000. 